\title{
Performance and Applications of Silicon Carbide Neutron Detectors in Harsh Nuclear Environments
}

\author{
Frank H. Ruddy ${ }^{1}$, Laurent Ottaviani ${ }^{2}$, Abdallah Lyoussi ${ }^{3}$, Christophe Destouches ${ }^{3}$, \\ Olivier Palais ${ }^{2}$, and Christelle Reynard-Carette ${ }^{2}$ \\ ${ }^{1}$ Ruddy Consulting, USA \\ ${ }^{2}$ Aix Marseille Univ, Université de Toulon, CNRS, IM2NP, Marseille, FRANCE \\ ${ }^{3}$ CEA Cadarache, FRANCE \\ FrankHRuddy@gmail.com
}

\begin{abstract}
Silicon carbide $(\mathrm{SiC})$ semiconductor is an ideal material for solid-state nuclear radiation detectors to be used in high-temperature, high-radiation environments. Such harsh environments are typically encountered in nuclear reactor measurement locations as well as high-level radioactive waste and/or "hot" dismantlingdecommissioning operations. In the present fleet of commercial nuclear reactors, temperatures in excess of $\mathbf{3 0 0}$ ${ }^{\circ} \mathrm{C}$ are often encountered, and temperatures up to $800{ }^{\circ} \mathrm{C}$ are anticipated in advanced reactor designs. The wide bandgap for $\mathrm{SiC}(3.27 \mathrm{eV})$ compared to more widely used semiconductors such as silicon $(1.12 \mathrm{eV}$ at room temperature) has allowed low-noise measurements to be carried out at temperatures up to $700{ }^{\circ} \mathrm{C}$. The concentration of thermally induced charge carriers in $\mathrm{SiC}$ at $700{ }^{\circ} \mathrm{C}$ is about four orders of magnitude less than that of silicon at room temperature. Furthermore, $\mathrm{SiC}$ radiation detectors have been demonstrated to be much more resistant to the effects of radiation-induced damage than more conventional semiconductors such as silicon, germanium, or cadmium zinc telluride (CZT), and have been demonstrated to be operational after extremely high gamma-ray, neutron, and charged-particle doses. The purpose of the present review is to provide an updated state of the art for $\mathrm{SiC}$ neutron detectors and to explore their applications in harsh high-temperature, high-radiation nuclear reactor applications. Conclusions related to the current state-of-the-art of $\mathrm{SiC}$ neutron detectors will be presented, and specific ideal applications will be discussed.

Keywords -Neutron detectors, silicon carbide, SiC, semiconductor, radiation damage.
\end{abstract}

\section{INTRODUCTION}

CILICON Carbide (SiC) semiconductor neutron detectors have many advantages for measurements in harsh hightemperature, high-radiation environments. The material properties of $\mathrm{SiC}$, particularly the $4 \mathrm{H}$ polytype [1], make operation in these environments more feasible than for other conventional semiconductors such as $\mathrm{Si}, \mathrm{Ge}$, and $\mathrm{CZT}$ (Cadmium Zinc Teluride). The 3.27-eV bandgap for $4 \mathrm{H} \mathrm{SiC}$ enables low-noise measurements at room temperature and temperatures up to at least $700{ }^{\circ} \mathrm{C}$. $\mathrm{SiC}$ has also been shown to be resistant to the cumulative effects of gamma, neutron, and charged-particle irradiation. Other factors that are advantageous for $\mathrm{SiC}$ include:

- $\quad$ high thermal conductivity (10-22 W/cm-K)

- a maximum breakdown field that is eight times that of silicon allowing higher biases to be applied resulting in higher drift velocities and more efficient charge collection

- a high saturated drift velocity (nearly twice that of silicon) leading to low charge trapping

The use of $\mathrm{SiC}$ as a radiation detector material was reviewed by Nava, et al. in 2008 [1], Strokan, et al. in 2009 [2] and Ruddy in 2013 [3]. Designs and properties of SiC neutron detectors were reviewed by Franceschini and Ruddy in 2011 [4]. The purpose of the present review is to provide an updated state of the art for $\mathrm{SiC}$ neutron detectors and to explore their applications in harsh high-temperature, high-radiation nuclear applications.

\section{SILICON CARBIDE DETECTOR DESIGNS}

By far the most prevalent design for SiC nuclear detectors is the epitaxial layer design shown schematically in Figure 1. [5-9] Although many different polytypes of $\mathrm{SiC}$ exist, $4 \mathrm{H}-\mathrm{SiC}$ is most frequently used for nuclear applications as discussed in detail in reference [1]. The conducting SiC substrate depicted in Fig. 1 typically has a nitrogen dopant concentration of about $10^{18} \mathrm{~cm}^{-3}$ and a thickness of about 300-350 $\mu \mathrm{m}$. An $\mathrm{n}^{-}$layer is grown onto the substrate layer using vapor-phase epitaxy. The dopant concentration, which corresponds to the unintentional residual nitrogen concentration, is typically less than about $10^{15} \mathrm{~cm}^{-3}$, and thicknesses ranging from a few $\mu \mathrm{m}$ up to $250 \mu \mathrm{m}$

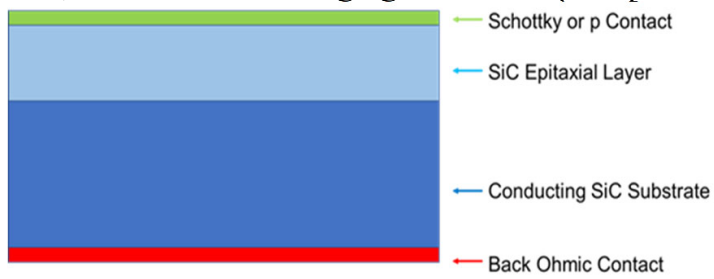

Fig. 1. Schematic representation of a $\mathrm{SiC}$ epitaxial diode detector structure. 
have been used. A metallic ohmic contact is applied to the back of the detector using a suitable material such as gold, titanium or nickel. The front contact can be either a Schottky contact using a suitable metal such as nickel or a $\mathrm{p}^{+}$contact formed by diffusing or implanting materials such as aluminum, phosphorus, or boron [5].

If a reverse bias is applied to the $\mathrm{SiC}$ diode (negative Schottky or $\mathrm{p}$ contact relative to the back ohmic contact), charge carriers are depleted from the epitaxial layer, and this depleted or intrinsic $\mathrm{SiC}$ layer corresponds to the active layer of the detector. The thickness of the depleted region, measured from the Schottky contact into the epitaxial layer, increases with reverse bias, $\mathrm{V}$, according to the following approximation

$$
d \cong\left[\frac{2 \varepsilon V}{e N}\right]^{1 / 2}
$$

where $\varepsilon$ is the dielectric constant for $\mathrm{SiC}, e$ is the electron charge and $\mathrm{N}$ is the nitrogen concentration. It can be seen that the depletion thickness is directly proportional to the square root of the applied voltage and inversely proportional to the square root of the dopant concentration. Therefore, to achieve large active volumes with thick epitaxial layers, one must have low nitrogen concentrations and/or apply high bias voltages. In practice, one might be constrained to voltages less than $1000 \mathrm{~V}$ (to protect the counting chain electronics from voltage discharges). Therefore, thick epitaxial layers with the lowest possible dopant concentrations are desirable. As discussed in reference [3], state-of-the-art $\mathrm{SiC}$ epitaxy is limited to nitrogen concentrations of about $10^{13} \mathrm{~cm}^{-3}$, but a goal of $10^{12} \mathrm{~cm}^{-3}$ is reasonable [10].

\section{NEUTRON RESPONSE MEASUREMENTS}

Neutrons have no electrical charge and are not capable of producing ionization directly in a detector. Therefore, as with all neutron detectors, $\mathrm{SiC}$ neutron detectors require a nuclear reaction to form reaction products that are capable of producing ionization within the detector active volume. For thermalneutron detection, the $\left.{ }^{10} \mathrm{~B}(\mathrm{n}, \alpha)\right)^{7} \mathrm{Li}$ and ${ }^{6} \mathrm{Li}(\mathrm{n}, \alpha)^{3} \mathrm{H}$ reactions have proven useful $[4,11]$, because solid-state compounds of boron and lithium are readily available and can be configured to allow the energetic charged-particle reaction products to enter the detector active volume [4-6,12]. In practice, the thermalneutron convertor material can be in the form of a thin layer juxtaposed near the active volume or can be incorporated into the detector by ion implantation [13] or diffusion [14].

Fast neutrons can be detected by ionization produced by ions resulting from nuclear reactions with silicon or carbon atoms in or near to the SiC active volume of the detector. A partial list of reactions is shown in Table I. [4] Other more complex reactions such as $(n, 2 n),(n, p n),(n, n \alpha)$, etc. are also possible as well as reactions with less abundant isotopes of carbon and silicon. For neutron spectra derived from down-scattering of fission neutrons, the response of a $\mathrm{SiC}$ detector will be dominated by the detection of energetic ${ }^{12} \mathrm{C}$ and ${ }^{28} \mathrm{Si}$ ions from $(\mathrm{n}, \mathrm{n}$ ') elastic and inelastic scattering reactions, because the average energy of fission neutrons is $\sim 2 \mathrm{MeV}$ with most of the neutrons having energies less than $6 \mathrm{MeV}$. Those threshold reactions that are energetically possible will add to the pulse-height continuum, because the incident neutron spectrum is a distribution of
TABLE I

FAST-NEUTRON INDUCED REACTIONS IN SILICON CARBIDE

\begin{tabular}{|c|c|}
\hline Reaction & $\begin{array}{c}\text { Threshold Energy } \\
\text { (MeV) }\end{array}$ \\
\hline${ }^{12} \mathrm{C}\left(\mathrm{n}, \mathrm{n}^{\prime}\right){ }^{12} \mathrm{C}$ (elastic scattering) & 0 \\
\hline${ }^{28} \mathrm{Si}\left(\mathrm{n}, \mathrm{n}^{\prime}\right)^{28} \mathrm{Si}$ (elastic scattering) & 0 \\
\hline${ }^{12} \mathrm{C}\left(\mathrm{n}, \mathrm{n}^{\prime}\right){ }^{12} \mathrm{C}$ (first excited state) & 4.809 \\
\hline${ }^{28} \mathrm{Si}\left(\mathrm{n}, \mathrm{n}^{\prime}\right)^{28} \mathrm{Si}$ (first excited state) & 1.843 \\
\hline${ }^{12} \mathrm{C}(\mathrm{n}, \alpha)^{9} \mathrm{Be}$ & 6.180 \\
\hline${ }^{28} \mathrm{Si}(\mathrm{n}, \alpha)^{25} \mathrm{Mg}$ & 2.749 \\
\hline${ }^{12} \mathrm{C}(\mathrm{n}, \mathrm{p})^{12} \mathrm{~B}$ & 13.643 \\
\hline${ }^{28} \mathrm{Si}(\mathrm{n}, \mathrm{p})$ & 3.999 \\
\hline
\end{tabular}

energies leading to a distribution of recoil-ion energies.

A comparison of the thermal-neutron and down-scattered fission-neutron responses for a $\mathrm{SiC}$ detector is shown in Fig. 2, which has been reproduced from Reference 15 . When the ${ }^{6} \mathrm{LiF}$

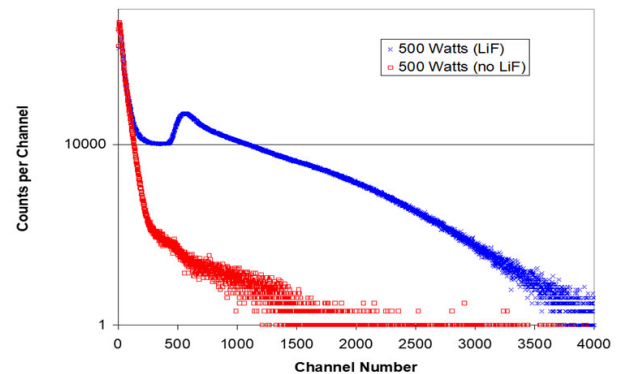

Fig. 2. Comparison of the neutron response of a $500-\mu \mathrm{m}$ diameter $\mathrm{x} 3-\mu \mathrm{m} \mathrm{SiC}$ Schottky diode to reactor fission neutrons with and without a $24.2-\mu \mathrm{m}{ }^{6} \mathrm{LiF}$ convertor foil (Figure reproduced from Reference 15).

converter foil is present, the detector response is dominated by the ${ }^{4} \mathrm{He}$ and ${ }^{3} \mathrm{H}$ ions produced by thermal-neutron reactions, and the events from fast-neutron induced reactions are obscured.

The fast-neutron spectrum (no converter foil) shown in Fig. 2 is a continuum dominated by elastic and inelastic neutron scattering reactions with carbon and silicon atoms in the $\mathrm{SiC}$ detector as discussed previously. The events below channel 300 are due primarily to gamma-ray induced secondary-electrons. The ranges of these electrons in $\mathrm{SiC}$ are large compared to the dimensions of the detector active volume resulting in only a fraction of the energy from each being detected. Although only a featureless low-energy continuum results, the detector response to gamma rays has been shown to be linear. [16-18] The fast-neutron response is complex and results in no peaks in the spectrum. Nevertheless, incident neutron energy information is present as shown by the data in Fig 3. [19]. The average energy of neutrons from fission of ${ }^{252} \mathrm{Cf}$ is $2.15 \mathrm{MeV}$, whereas the ${ }^{241} \mathrm{Am}-\mathrm{Be}$ source produces a much higher average energy of $4.5 \mathrm{MeV}$. The ${ }^{241} \mathrm{Am}-\mathrm{Be}$ detector response continuum is clearly shifted to higher pulse heights compared to the ${ }^{252} \mathrm{Cf}$

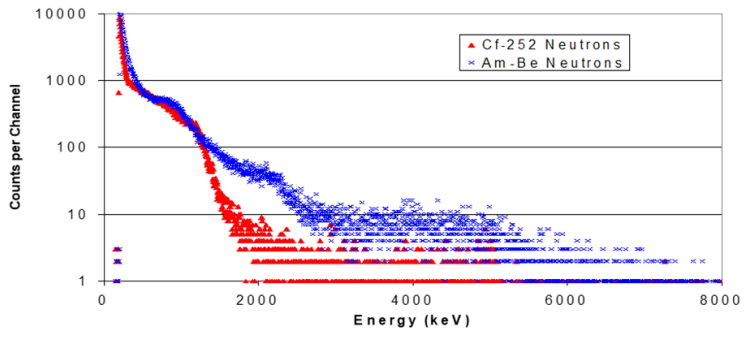

Fig. 3. Comparison of the responses of a SiC detector to fission neutrons from ${ }^{252} \mathrm{Cf}$ and neutrons from an ${ }^{241} \mathrm{Am}$-beryllium source. (Figure reproduced from Reference 19) 
response spectrum. In order to extract neutron energy-spectrum information from the pulse-height response, a complex unfolding procedure using a combination of neutron transport and recoil range calculations is required [20].

In the case of monoenergetic neutrons impinging on a $\mathrm{SiC}$ detector, peaks will be present for those reactions that result only in charged-particle products. For example, the ${ }^{12} \mathrm{C}(\mathrm{n}, \alpha){ }^{9} \mathrm{Be}$ reaction (see Table I) results only in ${ }^{4} \mathrm{He}$ and ${ }^{9} \mathrm{Be}$ ions which share the energy of the incident neutron plus the reaction energy. Therefore, a peak will be observed corresponding to ionization resulting from a total energy of $8298.8 \mathrm{keV}$ being deposited in the detector active volume. The response spectrum for a $\mathrm{SiC}$ detector exposed to $14.1 \mathrm{MeV}$ neutrons from a Deuterium-Tritium (DT) neutron generator is shown in Fig. 4, which has been reproduced from Reference 19.

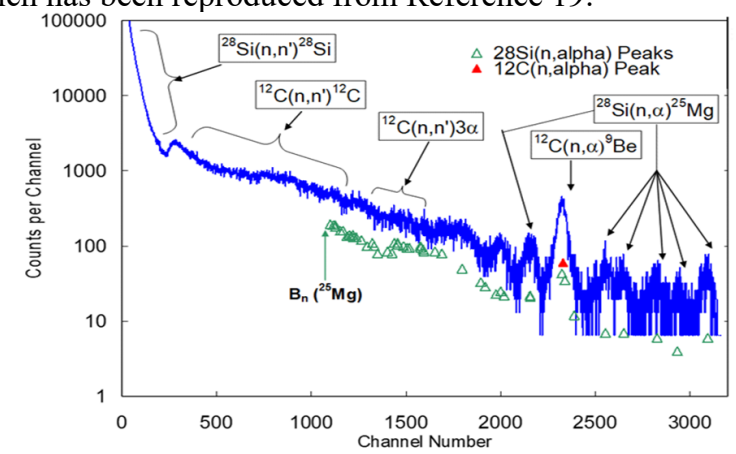

Fig. 4. Response spectrum for a $6 \mathrm{~mm}^{2}$ x $100 \mu \mathrm{m} \mathrm{SiC}$ detector exposed to 14.1 $\mathrm{MeV}$ DT neutrons. (Reproduced from Reference 19)

In addition to the prominent peak from the ${ }^{12} \mathrm{C}(\mathrm{n}, \alpha){ }^{9} \mathrm{Be}$ reaction, a family of peaks corresponding to the ${ }^{28} \mathrm{Si}(\mathrm{n}, \alpha)^{25} \mathrm{Mg}$ reaction is also present. The highest-energy peak corresponds to the production of the ground state of ${ }^{25} \mathrm{Mg}$ with the deposition of a total energy of $11,346 \mathrm{keV}$ in the $\mathrm{SiC}$ detector active volume. The other peaks in this set correspond to excited states of ${ }^{25} \mathrm{Mg}$ where less energy is deposited in the detector. The difference in energy corresponds to gamma rays produced when these excited states of ${ }^{25} \mathrm{Mg}$ decay to the ground state. As the energies of these excited states increases, the energy spacing between them decreases, and the peaks are not resolved above about the tenth excited state. The higher energy states will produce a continuum of events up to the ${ }^{25} \mathrm{Mg}$ neutron binding energy, $B_{n}$, above which the ${ }^{28} \mathrm{Si}(\mathrm{n}, \mathrm{n} \text { ' } \alpha)^{24} \mathrm{Mg}$ reaction will dominate. Since the energy of the neutron produced in this reaction is not fixed, no peaks will result from these reactions.

Continua from elastic and inelastic neutron scattering as well as more complex reactions such as ${ }^{12} \mathrm{C}\left(\mathrm{n}, \mathrm{n}^{\prime}\right) 3 \alpha$ are also present. No single peak is observed for these reactions, because the energy of the reaction product neutron is not fixed.

The neutron responses for $\mathrm{SiC}$ detectors have been shown to be linear for thermal [12,21], epithermal [16,17], fast [15] and 14-MeV neutrons [22].

\section{NEUTRON-RESPONSE MEASUREMENTS AT HIGH TEMPERATURES}

Some applications such as fusion-reactor technologies require stable measurement methods to detect neutrons and charged particles under extreme conditions such as high temperatures and high magnetic fields. To maintain the fusion process, it is mandatory to measure simultaneously the neutron flux and the tritium breeding ratio.

Specific fast neutron detectors, based on $4 \mathrm{H}-\mathrm{SiC}$ pn diodes, were developed in the framework of the European I_SMART project [23]. Their characteristics were measured at room temperature and compared with a single-crystal chemical vapor deposited (sCVD) diamond-based detector. Measurements were carried out at the DT neutron generator at Technical University of Dresden (TUD) at a fluence rate of about $9.4 \times 10^{6} \mathrm{~cm}^{-2}-\mathrm{s}^{-1}$ with a neutron energy of $14.12 \mathrm{MeV}$.

Both detectors produced pulse-height spectra with the wellresolved peak due to the ${ }^{12} \mathrm{C}(\mathrm{n}, \alpha){ }^{9} \mathrm{Be}$ reaction. The count rate of the diamond-based detector was higher than that of the SiCbased detector as a consequence of the higher thickness of the diamond active detection volume. The energy resolution of the ${ }^{12} \mathrm{C}(\mathrm{n}, \alpha){ }^{9} \mathrm{Be}$ peak was slightly better for the $4 \mathrm{H}-\mathrm{SiC}$-based detector (260 keV at FWHM which corresponds to $3.09 \%$ ), with respect to $303 \mathrm{keV}$ (3.6\%) for the diamond detector. An important phenomenon is the improvement of the energy resolution with increased neutron flux for the $\mathrm{SiC}$ detector, in complete opposition to the behavior of diamond [23].

Several prototypes were also tested in industrial conditions at the fast neutron generator at Schlumberger (Clamart, France), at room temperature and at $106^{\circ} \mathrm{C}$ [24]. The spectra showed good stability, preserving features over the whole temperature range. Prototypes with gold metallic contacts were then tested up to $500{ }^{\circ} \mathrm{C}$ at the DT neutron generator at the TUD [25]. In the recorded spectra, the different signal structures arising from high-energy deep inelastic reactions can be distinguished, independently of the temperature (see Fig. 5). The most prominent orientation point in the spectrum is the full energy peak of the ${ }^{12} \mathrm{C}(\mathrm{n}, \alpha){ }^{9} \mathrm{Be}$ reaction, which can be clearly distinguished at all the applied temperatures.

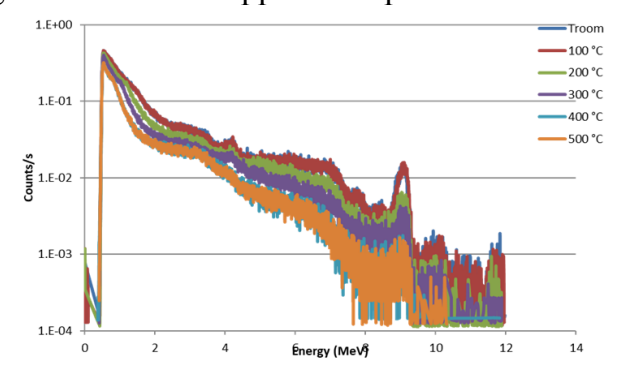

Fig. 5. Resulting energy spectra recorded during irradiation tests of SiC-based detectors with $14 \mathrm{MeV}$ neutrons at different ambient temperatures. (Figure reproduced from reference 25 ).

Abubakar, et al. [26] reported stability of the SiC-based alpha detector signal at $500 \mathrm{~K}\left(227^{\circ} \mathrm{C}\right)$ over a period of 18 hours.

No temperature-induced polarization effect has been observed to date with epitaxial Silicon Carbide, in contrast to the case of diamond where this effect appears above

$600 \mathrm{~K} \quad\left(327^{\circ} \mathrm{C}\right)[27]$.

\section{RADIATION DAMAGE EFFECTS IN SILICON CARBIDE DETECTORS}

Whereas conventional neutron detectors such as fission chambers and self-powered neutron detectors exhibit excellent resistance to the cumulative damaging effects of radiation, some monitoring applications are potentially better suited to 
semiconductor detectors. Common semiconductor detectors based on silicon or germanium are not only limited to lowtemperature operation, because of low band gaps, but also have low service lifetimes due to radiation damage effects. Therefore, these detectors have been of little use in harsh nuclear environments where large doses of gamma rays, neutrons and charged particles must be tolerated.

For example, silicon detectors show increasing leakage current when exposed to radiation due to the formation of defects that correspond to charge-donor levels in the band gap. Charge-trapping sites are also produced, but the increased leakage current is the primary radiation-damage limitation for the use of silicon detectors and is an indirect consequence of the low band gap for silicon.

On the other hand, wide band-gap semiconductor detector such as $\mathrm{SiC}$ are limited more by the accumulation of chargetrapping sites. Increased leakage current due to the formation of charge-donor states is less due to the larger band gap.

$\mathrm{SiC}$ has been shown to be highly resistant to the effects of radiation damage. The effects of large gamma-ray dose on the performance of $\mathrm{SiC}$ detectors have been investigated by several groups. Kang, et al. [28] showed that irradiating $6 \mathrm{H} \mathrm{SiC} \mathrm{diodes}$ with a dose of $120 \mathrm{kGy}$ of ${ }^{60} \mathrm{Co}$ gamma rays lead to a leakagecurrent decrease. Metzger, et al. [29], observed no change in the ${ }^{60} \mathrm{Co}$ gamma-ray detection efficiency of $6 \mathrm{H} \mathrm{SiC}$ photodiodes after a $1.080 \mathrm{MGy}$ dose of ${ }^{60} \mathrm{Co}$ gamma rays, and Kinoshita, et al.[30], observed no change in the $100 \%$ charge-collection efficiency of $6 \mathrm{H} \mathrm{SiC} \mathrm{p-n} \mathrm{diodes} \mathrm{after} \mathrm{a}{ }^{60} \mathrm{Co}$ gamma-ray dose of 2.5 MGy.

Ruddy and Seidel $[31,32]$ irradiated $4 \mathrm{H} \mathrm{SiC} \mathrm{Schottky} \mathrm{diodes}$ to a cumulative ${ }^{137} \mathrm{Cs}$ gamma-ray dose of $22.7 \mathrm{MGy} .{ }^{137} \mathrm{Cs}$ gamma rays were used to simulate the radiation environment of spent-fuel assemblies five years after discharge from a nuclear power reactor. The irradiated detector was found to perform well as a detector for fast ${ }^{252} \mathrm{Cf}$ fission neutrons and for $14-\mathrm{Mev}$ D-T neutrons [32].

Whereas the radiation effects of gamma rays on the response and operational lifetimes of $\mathrm{SiC}$ detectors are minor, the effects of charged particle and fast neutron damage are more formidable. For $\mathrm{SiC}$ detectors exposed in neutron environments, the radiation effects of fast neutrons as well as the charged particles produced by neutron convertor reactions (e.g., $\left.\left.\left.{ }^{6} \mathrm{Li}[\mathrm{n}, \alpha]^{3} \mathrm{H}\right),{ }^{10} \mathrm{~B}[\mathrm{n}, \alpha]\right]^{7} \mathrm{Li},{ }^{235} \mathrm{U}[\mathrm{n}, \mathrm{f}]\right)$ are both primary concerns.

An early neutron-damage study carried out by Ferber and Hamilton [33] showed that good alpha-particle spectrometry results were obtained with a $\mathrm{SiC}$ diode equipped with a ${ }^{235} \mathrm{U}$ convertor foil that had been exposed to a thermal neutron fluence of $6 \times 10^{15} \mathrm{~cm}^{-2}$. However, the fast-neutron fluence was not reported, and any radiation damage to the detector would have been caused by fast neutrons and fission fragments.

Tikhomirova, et al. [34] noted degradation of Berylliumdoped $6 \mathrm{H} \mathrm{SiC}$ detectors at neutron fluences greater than $10^{13}$ $\mathrm{cm}^{-2}$ for devices using a uranium convertor foil. However, the degradation was more likely due to the fission product ions from the convertor foil than from the neutrons impinging on the detector [4].

Seshadri, et al., [6] found that the charge collection efficiency for ${ }^{238} \mathrm{Pu}$ decreased systematically, and that selfbiased operation was not possible following an accumulated fast-neutron $(\mathrm{E}>1 \mathrm{MeV})$ fluence of $5.7 \times 10^{16} \mathrm{~cm}^{-2}$. The reduction in charge-collection efficiency was systematic and corresponded to a carrier removal rate of $9.7 \pm 0.7 \mathrm{~cm}^{-1}$, which the authors attributed to the introduction of deep-level traps by fast-neutron interactions.

Dulloo, et al., [12,21] showed that the thermal-neutron response of a $\mathrm{SiC}$ Schottky diode with a ${ }^{6} \mathrm{LiF}$ convertor foil was indistinguishable from that of an unirradiated detector after a fast-neutron $(\mathrm{E}>1 \mathrm{MeV})$ fluence of $1.3 \times 10^{16} \mathrm{~cm}^{-2}$.

Nava, et al., [35] observed only minor $(\sim 20 \%)$ losses in charge-collection efficiency for $4 \mathrm{H} \mathrm{SiC} \mathrm{Schottky} \mathrm{diodes} \mathrm{at} \mathrm{1-}$ $\mathrm{MeV}$ neutron fluences up to $10^{15} \mathrm{~cm}^{-2}$. At fluences higher than $10^{15} \mathrm{~cm}^{-2}$ the charge-collection losses increase monotonically to $\sim 80 \%$ loss at $8 \times 10^{15} \mathrm{~cm}^{-2}$.

Lo Giudice, et al., [36] irradiated large area 4H-SiC Schottky diodes equipped with a ${ }^{6} \mathrm{LiF}$ convertors with epithermal neutrons and observed less than $0.3 \%$ decrease in the count rate after a neutron fluence of $10^{13} \mathrm{~cm}^{-2}$. They attributed this minor decrease to alpha-particle damage from the ${ }^{6} \operatorname{Li}(\mathrm{n}, \alpha)^{3} \mathrm{H}$ convertor layer. The more energetic ${ }^{3} \mathrm{H}$ ions would be expected to produce less localized damage.

Afanasyev, et al., [37] examined the photosensitivity of $\mathrm{SiC}$ UV photodiodes and observed no change in performance after a fast-neutron fluence of $5 \times 10^{12} \mathrm{~cm}^{-2}$ but observed reduction of the photosensitivity of their devices at higher fluences up to $1 \times 10^{14} \mathrm{~cm}^{-2}$.

A study by $\mathrm{Wu}$, et al. [38] found that the charge collection efficiency for self-biased $4 \mathrm{H} \mathrm{SiC} \mathrm{Schottky} \mathrm{diodes} \mathrm{reduced} \mathrm{to}$ $1.3 \%$ of the unirradiated value after irradiation with a fastneutron fluence of $8.26 \times 10^{14} \mathrm{~cm}^{-2}$.

Systematic investigations were made by Ruddy, et al., [39] of the effects on detector performance of both fast $(\mathrm{E}>1 \mathrm{MeV})$ neutrons and energetic ${ }^{3} \mathrm{H}$ and ${ }^{4} \mathrm{He}$ ions from reactions in a ${ }^{6} \mathrm{LiF}$ convertor layer. Following neutron irradiations, the detectors were tested with a ${ }^{238} \mathrm{Pu}$ alpha-particle source as described in Reference [5] in order to evaluate charge-collection efficiency as a function of accumulated neutron and charged-particle fluence. Irradiations were carried out at two temperatures, $45^{\circ} \mathrm{C}$ and $230{ }^{\circ} \mathrm{C}$. The neutrons-only results are shown in Fig. 6 , where ${ }^{238} \mathrm{Pu}$ pulse height, which was taken to be a measure of

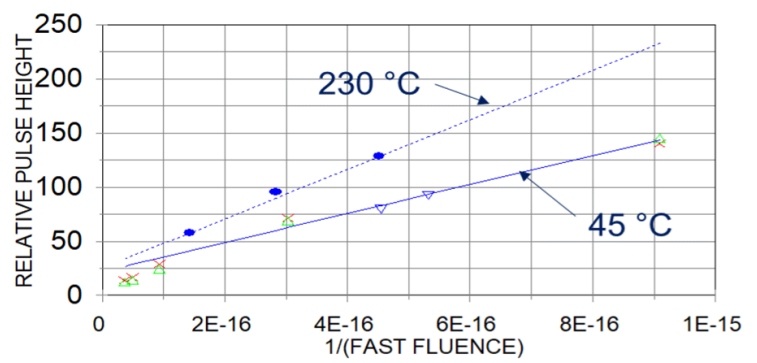

Fig. 6. Effect of elevated temperature during neutron irradiation on the observed pulse heights from a ${ }^{238} \mathrm{Pu}$ alpha test source. Pulse height is plotted as a function of reciprocal fast neutron fluence. The symbols refer to different irradiated SiC detectors. (Adapted from Reference 39)

charge-collection efficiency, is plotted as a function of reciprocal accumulated neutron fluence. The results at both temperatures are fit well by a straight line, consistent with the predictions $[6,39,40]$ of a simple first-order model which assumes that loss of charge carriers is directly proportional to the density of charge traps produced in the $\mathrm{SiC}$ active volume 
by fast neutrons. A similar relationship was observed for the charged-particle results, where ${ }^{238} \mathrm{Pu}$ pulse height was found to be proportional to the reciprocal of the calculated displacements caused by the fast neutrons, ${ }^{3} \mathrm{H}$ ions and ${ }^{4} \mathrm{He}$ ions.

It can be seen from Fig. 6 that the $230{ }^{\circ} \mathrm{C}$ irradiations result in significantly higher charge collection in the $\mathrm{SiC}$ detectors than the $45^{\circ} \mathrm{C}$ irradiations. It was concluded by the authors [39] that elevated temperature mitigates the effects of the radiation damage on charge collection, but that more data are needed at temperatures of $300^{\circ} \mathrm{C}$ and higher. An important implication of these results is that operation in an elevated-temperature environment may extend the service lifetime of a $\mathrm{SiC}$ neutron detector.

A similar conclusion was reached by McGarrity, et al.[41,42], who reported results for the performance of $6 \mathrm{H} \mathrm{SiC}$ JFETs irradiated with neutrons at temperatures up to $300{ }^{\circ} \mathrm{C}$.

\section{APPLICATIONS IN HARSH NUCLEAR ENVIRONMENTS}

\section{A. Spent Fuel Monitoring}

During reactor irradiation, nuclear fuel acquires a neutron specific activity, primarily due to the buildup of higher actinides by successive neutron reactions originating with the ${ }^{238} \mathrm{U}$ component of the fuel. [16-18] These actinides produce neutrons through spontaneous fission of isotopes such as ${ }^{240} \mathrm{Pu}$, ${ }^{242} \mathrm{Cm}$ and ${ }^{244} \mathrm{Cm}$. During the first operating cycle, ${ }^{240} \mathrm{Pu}$ will dominate, but for a fully burnt fuel assembly several years after discharge, the primary neutron-producing isotope will be 18.1 year ${ }^{244} \mathrm{Cm}$. In the case of oxide fuels, neutrons are also produced by the alpha-emitters present through ${ }^{18} \mathrm{O}(\alpha, \mathrm{n})$ and ${ }^{17} \mathrm{O}(\alpha, \mathrm{n})$ reactions. Gamma rays will also be present primarily from the fission-product inventory present in the fuel. For example, a Pressurized Water Reactor fuel assembly with a burnup of 25,655 $\mathrm{MWd} / \mathrm{MTU}$ had a total surface neutron fluence rate of $8000 \mathrm{~cm}^{-2}-\mathrm{s}^{-1}$ at midplane three years after discharge [43], and typical gamma dose rates in spent-fuel environments are in the $10^{2}-10^{3} \mathrm{~Gy} / \mathrm{hr}$ range [17-18].

Natsume, et al. [18] tested a SiC neutron detector in a spent fuel pool, and over a 2050-hour (85.4-day) period of continuous monitoring the detector neutron and gamma response did not change or deteriorate. The fluence rates were $180 \mathrm{~cm}^{-2}-\mathrm{s}^{-1}$ and $11 \mathrm{~Gy} / \mathrm{hr}$ for fast neutrons and gamma rays, respectively. Both the gamma-ray and neutron count rates were stable to precisions of $1.7 \%$ and $2.9 \%$ for gamma rays and neutrons, respectively.

The high radiation resistance, stability in elevated and changing temperatures and small size and versatility of SiC detectors make them extremely useful for spent-fuel monitoring applications.

\section{B. Safeguards Monitoring}

A related safeguards-monitoring application is long-term monitoring of spent fuel. The axial distribution of the neutron emission rate at the surface of a spent fuel assembly will depend on the burnup history of the assembly [43]. Deviations from the expected distributions can be used as an indicator of off-normal conditions resulting from diversion of fuel rods, mechanical or corrosive deterioration of the assembly, water incursion, etc. $\mathrm{SiC}$ neutron detectors can be used to monitor the neutron energy spectrum as a function of axial position either by affixing detectors near the surface of the assembly or inserting a stringer of detectors within an assembly guide tube.

It has been demonstrated [39] that after a fast $(\mathrm{E}>1 \mathrm{MeV})$ fluence of $1.7 \times 10^{17} \mathrm{~cm}^{-2}-\mathrm{sec}^{-1}$, SiC neutron detectors are still functional. In a typical spent fuel neutron environment, it would take 5-50 million years to reach this dose. It has also been shown that $\mathrm{SiC}$ detectors operate well after a ${ }^{137} \mathrm{Cs}$ dose of 22.7 MGy [39]. If a $\mathrm{SiC}$ detector were to be placed adjacent to or within a spent fuel assembly immediately after discharge and left in place indefinitely, this dose would never be reached. Therefore, SiC neutron detectors are capable of continuously monitoring a spent fuel assembly following discharge from the reactor, during transportation and following deposition in a spent fuel repository.

\section{Monitoring of Nuclear Fusion Devices}

Monitoring of nuclear fusion devices and reactors is required to obtain energy on important operational parameters such as fusion power and plasma temperature. In a fusion power reactor, such as the International Thermonuclear Experimental Reactor (ITER) currently under construction in Cadarache, France, the neutron intensity and energy distribution can be used to deduce information on the fusion power and ion temperature [44].

Fusion reactions are produced in a dense, high-temperature, magnetically confined plasma. The primary energy-producing reaction is the DT reaction accompanied by $14-\mathrm{MeV}$ neutrons, but DD and other secondary reactions also take place. The plasma and its surroundings are an extremely harsh measurement environment with temperatures exceeding $150,000,000{ }^{\circ} \mathrm{C}$. In Test Blanket Modules in the ITER wall, temperatures can reach up to $920^{\circ} \mathrm{C}$ in the breeder material, up to $550{ }^{\circ} \mathrm{C}$ in the EUROFER structure, and up to $650{ }^{\circ} \mathrm{C}$ in the neutron multiplier. Magnetic fields of $\sim 4 \mathrm{~T}$ are present and measurements are confined to extremely limited access/space.

$\mathrm{SiC}$ neutron detectors are potentially capable of providing detailed neutron spectra under these conditions as discussed in Sections III-IV. Peaks from ${ }^{12} \mathrm{C}(\mathrm{n}, \alpha){ }^{9} \mathrm{Be}$ and ${ }^{28} \mathrm{Si}(\mathrm{n}, \alpha){ }^{25} \mathrm{Mg}$ reactions can provide information on the D-T fusion energy as well as energy width. The reaction peaks can be measured to an energy resolution of $2.2-2.3 \%$ FWHM, equal to the energy resolution obtainable with $\mathrm{Si}$ detectors [19], which have no prospects for operating in a fusion reactor environment.

Concepts are also being developed to demonstrate on-line breeding of tritium to fuel the fusion reaction. Test Blanket Modules integrated inside the tokamak wall will produce tritium via neutron reactions with lithium. $\mathrm{SiC}$ neutron detectors can be used to monitor the thermal-neutron fluence rate at key locations in and around the Test Blanket Modules. If a $\mathrm{LiF}$ convertor is used, the detector count-rate is a direct measure of the tritium production reaction rate.

In addition to neutron measurements, $\mathrm{SiC}$ charged-particle detectors can be deployed to obtain information on yields of charged particles $\left({ }^{1} \mathrm{H},{ }^{2} \mathrm{H},{ }^{3} \mathrm{H},{ }^{3} \mathrm{He},{ }^{4} \mathrm{He}\right)$ from fusion and breeder reactions.

\section{Monitoring of Test and Research Reactors}

New test and research reactors are coming online to address new requirements that can not be met by the current aging fleet. An example is the Jules Horowitz Reactor (JHR), which is 
currently under construction at CEA Cadarache, France [45] These reactors will address nuclear materials and fuels irradiation testing needs being generated by advanced commercial nuclear power plant designs that employ innovative high-temperature coolants such as liquid metals and molten salts. Neutron monitoring is required for testing in the hightemperature and high fluence-rate environments typical of reactors such as JHR.

In the framework of the European I_SMART project [46], new $4 \mathrm{H}-\mathrm{SiC}$ based neutron detectors were developed and tested and have been demonstrated to be able to operate in harsh environments and detect both fast and thermal neutrons. [4749 ] Prototypes with various designs were fabricated, some of them optimized for thermal neutron detection via a specific boron converter layer (either deposited on top of the structure or implanted in the anode ohmic contact layer). These detectors have been tested at the MINERVE zero power reactor and in the SCK $\cdot \mathrm{CEN}$ BR1 reactor (at fluence rates of the order of $10^{9}$ $\left.\mathrm{cm}^{-2}-\mathrm{s}^{-1}\right)$ on prototypes of various sizes, with and without ${ }^{10} \mathrm{~B}$ (implanted at room temperature or at $400{ }^{\circ} \mathrm{C}$ ). These measurements proved the linearity of the detector responses with reactor power. In addition, thermal neutron detection spectra were recorded as a function of bias voltage. Zero-bias operation was demonstrated and shown to give the best gammaray discrimination consistent with the thin active volume produced by the zero-bias $\mathrm{p}-\mathrm{n}$ diode potential.

Tests are planned in the Joseph Stefan Institute TRIGA reactor at fluence rates of the order of $10^{12} \mathrm{~cm}^{-2}-\mathrm{sec}^{-1}$, leading to high fluence and fluence -rate testing at the 100-MW JHR.

\section{E. Monitoring of Advanced Nuclear Power Reactors}

Many of the advanced nuclear power reactors under development utilize extremely high-temperature coolant concepts. See, for example Reference [50] The Natrium Reactor is a sodium-cooled fast reactor with a molten-salt energy storage system. The KP-FHR reactor employs fluoridesalt cooling, and the Molten Chloride Reactor also requires molten-salt cooling. The newly developed reactors will require neutron monitoring at temperatures up to $850^{\circ} \mathrm{C}$, which will present challenges to the present gas-filled and self-powered neutron detector technology. SiC neutron detectors have been demonstrated at temperatures up to $700{ }^{\circ} \mathrm{C}$ and likely can operate at higher temperatures $\left(4 \mathrm{H} \mathrm{SiC} \mathrm{sublimes} \mathrm{at} 2857^{\circ} \mathrm{C}\right)$.

\section{CONCLUSIONS AND RECOMMENDATIONS}

$\mathrm{SiC}$ neutron detectors are an emerging technology which provides many advantages for monitoring harsh nuclear environments. $\mathrm{SiC}$ detectors can operate up to at least $700{ }^{\circ} \mathrm{C}$ and have been shown to withstand high doses of gamma-rays, neutrons and charged particles. Additionally, measurements have shown that irradiation of $\mathrm{SiC}$ at high temperatures reduces the radiation damage effects of the irradiation.

More elevated-temperature data are needed to understand the effects of temperature on mitigation of radiation damage in $\mathrm{SiC}$. These effects are much more dramatic than those observed from post-irradiation annealing [39], and their understanding is crucially important for evaluating the applicability of $\mathrm{SiC}$ detectors in high-temperature, high-fluence nuclear environments.
It has been hypothesized [33] that so-called self-annealing operation may be possible with $\mathrm{SiC}$ detectors. If the rate of mitigation of radiation-induced damage at an elevated temperature is greater than or equal to the rate of introduction of radiation-induced damage, the effects of radiation should not limit the lifetimes of $\mathrm{SiC}$ detectors in that environment. Although an intriguing possibility, it remains to be demonstrated.

\section{REFERENCES}

[1] F. Nava, G. Bertuccio, A. Cavallini and E. Vittone, "Silicon Carbide and Its Use as a Radiation Detector Material," Meas. Sci. Technol., vol. 19, pp 1-25, Aug. 2008. http://iopscience.iop.org/0957-0233/19/10/102001

[2] N. Strokan, A. Ivanov, and A. Lebedev, "Silicon Carbide NuclearRadiation Detectors," in SiC Power Materials: Devices and Applications, (Z. Feng, Ed.), New York, NY, USA, Springer-Verlag, 2009, Chapter 11 pp 411-442.

[3] F. H. Ruddy, "Silicon Carbide Radiation Detectors: Progress, Limitations and Future Directions," Materials Research Society Online Proceedings vol. 5761, Nov. 2013

http://journals.cambridge.org/action/displayAbstract?fromPage $=$ online \& aid $=9071147$

[4] F. Franceschini and F. H. Ruddy, "Silicon Carbide Neutron Detectors," in Properties and Applications of Silicon Carbide (R. Gerhardt, Ed.), Chapter 13, Rijeka, Croatia, InTech, 2011, pp 275-296.

[5] F. H. Ruddy, A. R. Dulloo, J. G. Seidel, S. Seshadri and L. B. Rowland, "Development of a Silicon Carbide Radiation Detector," IEEE Trans. Nucl. Sci., vol. 45, pp 536-541, June 1998.

[6] S. Seshadri, A.R. Dulloo, F.H. Ruddy, J. G. Seidel, and L. B. Rowland, "Demonstration of a $\mathrm{SiC}$ neutron detector for high-radiation environments," IEEE Trans. Electron Devices, vol. 46, pp. 567-571, March 1999.

[7] F. Nava, P. Vanni, C. Lanzieri, and C. Canali, "Epitaxial Silicon Carbide Charge Particle Detectors," Nucl. Instr. Meth. A, vol. 437, pp 354-358, Dec. 1999.

[8] G. Bertuccio, R. Casiraghi, and F. Nava, "Epitaxial Silicon Carbide for X-Ray Detectors," IEEE Trans. Nucl. Sci., vol 48, pp 232-233, April 2001.

[9] M. Bruzzi, S. Lagomarsino, S. Nava, and S. Sciortino, "Characteristics of Epitaxial SiC Schottky Barriers as Particle Detectors," Diamond and Related Materials, vol. 12, pp 1205-1208, March 2003.

[10] G. Bertuccio, "HiTSiC: High Thickness Epitaxial Silicon Carbide Detectors," presentation given in Rome, September 25, 2006 (unpublished).

[11] G. F. Knoll, Radiation Detection and Measurement, $4^{\text {th }}$ Edition, New York, NY, USA, Wiley, 2019, pp 519-523.

[12] A. R. Dulloo, F. H. Ruddy, J. G. Seidel, J. M. Adams, J. S. Nico, and D. M. Gilliam, "The Neutron Response of Miniature Silicon Carbide Semiconductor Detectors," Nucl. Instr Meth. A, v. 422, pp 47-48, Feb. 1999.

[13] F. Issa, L. Ottaviani, D. Szalkai, L. Vermeeren, V. Vervisch, A. Lyoussi, R. Ferone, A. Kuznetsov, M. Lazar, A. Klix, O. Palais, and A. Hallén, "Improvements in Realizing 4H-SiC Thermal Neutron Detectors," ISRD 15 - International Symposium on Reactor Dosimetry, (A. Lyoussi [Ed.]), EPJ Web of Conferences, vol. 106, 05004, 2016.

[14] K. C. Mandal, T. A. Chowdhury, C. Oner, and F. H. Ruddy, "Design and Response Testing of Boron-Diffused Silicon Carbide Neutron Detectors for Dosimetry and Monitoring Applications," ASTM STP1608, (M. H. Sparks, K. R. Depriest, and D. W. Vehar, [Eds.]), W. Conshohocken, PA, USA, ASTM International, 2018, pp. 353-360.

[15] F. H. Ruddy, J. G. Seidel, T. E. Blue, and D. W. Miller, "Reactor Power Monitoring Using Silicon Carbide Fast Neutron Detectors," in PHYSOR-2006 - American Nuclear Society's Topical Meeting on Reactor Physics, LaGrange Park, Illinois, USA, American Nuclear Society, 2006.

[16] A. R. Dulloo, F. H. Ruddy, J. G. Seidel, C. Davison, T. Flinchbaugh, and T. Daubenspeck, "Simultaneous Measurement of Neutron and Gamma-Ray Radiation Levels from a TRIGA Reactor Core Using 
Silicon Carbide Semiconductor Detectors," IEEE Trans. Nucl. Sci, vol 46, pp 275-279, June1999.

[17] A. R. Dulloo, F. H. Ruddy, J. G. Seidel, T. Flinchbaugh, C. Davison, and T. Daubenspeck, "Neutron and Gamma Ray Dosimetry in SpentFuel Radiation Environments Using Silicon Carbide Semiconductor Radiation Detectors," in Reactor Dosimetry: Radiation Metrology and Assessment, ASTM STP 1398, (John G. Williams, David W. Vehar, Frank H. Ruddy, and David M. Gilliam, [Eds.]), W. Conshohoken, PA, USA, American Society for Testing and Materials, 2001, pp 683-690.

[18] T. Natsume, H. Doi, F. H. Ruddy, J. G. Seidel, and A. R. Dulloo, "Spent Fuel Monitoring with Silicon Carbide Semiconductor Neutron/Gamma Detectors," Journal of ASTM International, Online vol. 3, March 2006.

[19] F. H. Ruddy, J. G. Seidel, and F. Franceschini, "Measurements of the Recoil-Ion Response of Silicon Carbide Detectors to Fast Neutrons," in Reactor Dosimetry State of the Art 2008, (W. Voorbraak, L. Debarberis, P. D'hontd, and J. Wagemans, Eds.), London, England, World Scientific, 2009, pp 77-84.

[20] F. Franceschini and F. H. Ruddy "Simulation of the Response of Silicon Carbide Fast Neutron Detectors," in Reactor Dosimetry State of the Art 2008, (W. Voorbraak, L. Debarberis, P. D'hontd, and J. Wagemans, Eds.), London, England, World Scientific, 2009, pp 128-135.

[21] A. R. Dulloo, F. H. Ruddy, J. G. Seidel, J. M. Adams, J. S. Nico, and D. M. Gilliam, "The Thermal Neutron Response of Miniature Silicon Carbide Semiconductor Detectors," Nuclear Instr. and Meth. A, vol. 498, pp 415-423, Feb. 2003.

[22] A. R. Dulloo, F. H. Ruddy, J. G. Seidel, and B. Petrović, "Monitoring of D-T Accelerator Neutron Output in a PGNAA System Using Silicon Carbide Detectors," Applications of Accelerators in Research and Industry - Sixteenth International Conference, American Institute of Physics Conference Proceedings, vol. 576, p 499, September 2001.

[23] O. Obraztsova, L. Ottaviani, A. Klix, T. Döring, O. Palais, A. Lyoussi, "Comparing the response of a $\mathrm{SiC}$ and a SCVD Diamond detectors to 14 $\mathrm{MeV}$ neutron radiation," IEEE Transactions on Nuclear Science, vol. 65, pp. 2380-2384, Sept. 2018.

[24] R. Ferone, F. Issa, D. Szalkai, A. Klix, L. Ottaviani, S. Biondo, V. Vervisch, L. Vermeeren, R. Saenger, A. Lyoussi, "SiC-based neutron detector in quasi-realistic working conditions: efficiency and stability at room temperature and high temperatures under fast neutron irradiations," in 4th International Conference on Advancements in Nuclear Instrumentation Measurement Methods and their Applications (ANIMMA), IEEE, pp. 1-4, 2015.

[25] D. Szalkai, R. Ferone, F. Issa, A. Klix, M. Lazar, A. Lyoussi, L. Ottaviani, P. Tutto, V. Vervisch, "Fast Neutron Detection with 4H-SiC Based Diode Detector up to $500{ }^{\circ} \mathrm{C}$ Ambient Temperature," IEEE Trans. Nucl. Sci, vol. 63, pp 1491-1498, June 2016.

[26] Y.M. Abubakar, A. Lohstroh, and P.J. Sellin, "Stability of Silicon carbide particle detector performance at elevated temperatures," IEEE Transactions on Nuclear Science, vol. 62, pp. 2360-2366, October 2015.

[27] M. Angelone, S. Cesaroni, S. Loreti, G. Pagano, and M. Pillon, "High temperature response of a single CVD diamond detector operated in current mode," Nuclear Inst. And Meth. Phys. Res. A, vol. 943, Nov. 2019,162493

[28] S. M. Kang, J. H. Ha, S. H. Park, H. S. Kim, S. D. Chun, and Y. K. Kim, "Study of the Current-Voltage Characteristics of a SiC Radiation Detector Irradiated by Co-60 Gamma-Rays," Nuclear Inst. And Meth. Phys. Res. A, vol. 579, pp 145-147, Aug. 2007.

[29] S. Metzger, H. Henschel, O. Kohn, W. Lennartz, "Silicon Carbide Radiation Detector for Harsh Environments," IEEE Trans. Nucl Sci., vol. 49, pp 1351-1355, June 2002.

[30] A. Kinoshita, M. Iwami, K. Kobayashi, I. Nakano, R. Tanaka, T. Kamiya, A. Ohi, T. Oshima, Y. Fukushima, "Radiation Effect on pn-SiC Diode as a Detector," Nucl. Instr. and Meth. A, vol. 541, pp 213-220, April 2005.

[31] F. H. Ruddy and J. G. Seidel, "The Effects of Intense Gamma Irradiation on the Alpha-Particle Response of Silicon Carbide Semiconductor Radiation Detectors," Nucl. Inst. And Meth. Phys. Res. B, vol. 263, pp 163-168, Oct. 2007.
[32] F. H. Ruddy and J. G Seidel, "Effects of Gamma Irradiation on Silicon Carbide Semiconductor Radiation Detectors," IEEE Nuclear Science Symposium Conference Record, Paper \#4179063, pp 583-587, 2006.

[33] R. R. Ferber and G. N. Hamilton, "Silicon Carbide High-Temperature Neutron Detectors for Reactor Instrumentation," Nuclear Technology vol. 2, pp 246-251, June 1966.

[34] V. A. Tikhomirova, O. P. Fedoseeva and V. V. Bol'shakov, "Silicon Carbide Detectors as Fission-Fragment Counters in Reactors," Izmeritel'naya Tekhnika, vol.6, pp 67-68, June 1973.

[35] F. Nava, A. Castaldini, A. Cavallini, P. Errani and V. Cindro, "Radiation Detection Properties of 4H-SiC Schottky Diodes Irradiated Up to $10^{16}$ n/cm² by $1 \mathrm{MeV}$ Neutrons,", IEEE Trans. Nucl. Sci, vol. 53, pp $2977-$ 2982, Oct. 2006.

[36] A. Lo Giudice, F.Fasolo, E. Durisi, C. Manfredotti, E. Vittone, F. Fizzotti, A. Zanini, and G. Rosi, "Performance of 4H-SiC Schottky Diodes as Neutron Detectors," Nucl. Instr. and Meth. A, vol. 583, pp 177-180, Dec. 2007.

[37] A.V. Afanasyev, V.A. Ilyin, V.V. Luchinin, S.A. Reshanov, A. Schöner, K.A. Sergushichev and A.A. Smirnov, "Effect of neutron irradiation on epitaxial 4H-SiC PiN UV-photodiodes," Materials Science Forum, vol. 897, pp 614-617, May 2017.

[38] J. Wu, Y. Jiang, J. Lei, X. Fan, Y. Chen, M. Li, D. Zou and B. Liu, "Effect of Neutron Irradiation on Charge Collection Efficiency in 4HSiC Schottky Diode," Nucl. Instr. and Meth. A, pp 218-222, Jan. 2014.

[39] F. H. Ruddy, A. R. Dulloo and J. G. Seidel, "Study of the Radiation Resistance of Silicon Carbide Radiation Detectors," Trans.Am. Nucl. Soc., vol. 90, pp 348-349, June 2004.

[40] G. C. Messenger and M. S. Ash, The Effects of Radiation on Electronic Systems, New York, NY, USA, Van Nostrand Reinhold, 1991.

[41] F. B. McLean, J. M. McGarrity, C. J. Scozzie, C. W. Tipton, and W. M. DeLancey, "Analysis of Neutron Damage in HighTemperature Silicon Carbide JFETs," in High-Temperature Electronics, (R. Kirschman,Ed.), Institute of Electrical and Electronics Engineers, 1999, pp.530-540.

[42] C. J. Scozzie, J. M. McGarrity, J. Blackburn, and W. M. DeLancey, Silicon Carbide FETs for High Temperature Nuclear Environments," IEEE Trans. Nucl. Sci., vol. 43, pp 1642-1648, June 1996.

[43] R. Gold, F. H., Ruddy, E. P. Lippincott, W. N. McElroy, and J. H. Roberts, "Spent Thermal Reactor Fuel Assembly Characterization with Solid State Track Recorders," in Dosimetry Methods for Fuels Cladding and Structural Materials - Proceedings of the Third ASTM-Euratom Symposium on Reactor Dosimetry, (H.Röttger, [Ed.]), EUR-6813, Ispra, Italy, Commission of European Communities, pp. 858-867, Oct. 1980.

[44] L. Bertalot, V. Krasilnikov, L. Core, A. Saxena, N. Yukhnov, R. Barnsley, and M. Walsh, "Present Status of ITER Neutron Diagnostic Development," J. Fusion Energy, vol. 38, pp 283-290, July 2019.

[45] D. Iracane, and P. Yvon, "The JHR reactor: a multipurpose asset for materials," Clefs CEA, vol. 55, pp 102-105, 2007.

[46] A. Lyoussi, “I_SMART a Collaborative Project on Innovative Sensors for Material Ageing and Radiation Testing: European Innovative Project for SiC Applications in Harsh Media," KIC_Innoenergy,SSCV_SMART Proposal/Exhibit 1, 2012.

[47] F. Issa, V. Vervisch, L. Ottaviani, D. Szalkai, L. Vermeeren, A. Lyoussi, A. Kuznetsov, M. Lazar, A. Klix, O. Palais, and A. Hallen, "Radiation Silicon Carbide Detectors based on Ion Implantation of Boron," IEEE Trans. Nucl. Sci, Vol. 61, pp 2105-2111, Aug. 2014.

[48] F. Issa, L. Ottaviani, D. Szalkai, L. Vermeeren, V. Vervisch, A. Lyoussi, R. Ferone, A. Kuznetsov, M. Lazar, A. Klix, O.Palais, "4H-SiC Neutron Sensors Based on Ion Implanted ${ }^{10} \mathrm{~B}$ Neutron Converter Layer," IEEE Trans. Nucl. Sci, vol. 63, pp 1967-1980, June 2016.

[49] V. Radulovic, Y. Yamazaki, Z. Pastuovic, A. Sarbutt, K. Ambrozic, R. Bernat, Z. Eres, J. Coutinho, T. Ohshima, I. Capan, and L. Snoj, "Silicon Carbide neutron detector at the JSI TRIGA reactor for enhanced border and port security," Nucl. Inst. And Meth. Phys. Res. A, vol. 972, 164122, Aug. 2020.

[50] United States Department of Energy, "Advanced Reactor Development. Paving a Path to Commercialization" https://www.energy.gov/ne/articles/infographic-advanced-reactordevelopment . 